\title{
Poder de mercado bancario y crédito en Europa tras la crisis financiera global
}

\author{
Elena Cubillas \\ Nuria Suárez \\ Colegio Universitario de Estudios Financieros (CUNEF)
}

\section{Resumen}

Este trabajo analiza los efectos de la reciente crisis financiera en la competencia bancaria y la oferta de crédito en Europa. Los resultados obtenidos tras aplicar un procedimiento en dos etapas a una muestra de 610 entidades, proporcionan evidencia de cómo el impacto negativo de la crisis en la oferta de crédito es contrarrestado por el incremento en el poder de mercado bancario medio experimentado desde 2008. Este efecto se observa especialmente en entornos con menor calidad institucional, más exigentes en el cumplimiento del capital regulatorio, y allí donde no existen elevadas restricciones a las actividades bancarias no tradicionales.

Palabras clave: crédito bancario, crisis financiera, competencia bancaria, poder de mercado, calidad institucional, regulación bancaria.

Clasificación JEL: E51, G21, G28.

\section{Abstract}

This paper examines the effects of the global financial crisis on bank competition and credit supply in Europe. Results obtained by applying a 2SLS procedure over a sample of 610 banks provide evidence of the negative effect of the crisis period on bank lending. However, this negative impact is moderated by the increase of bank market power since 2008. These relationships are especially relevant in the case of countries with lower levels of institutional quality, with higher stringency of regulation on bank capital and in countries with lower levels of restrictions on non-traditional banking activities.

Keywords: bank credit, financial crisis, bank competition, market power, institutional quality, bank regulation.

JEL classification: E51, G21, G28.

\section{Introducción}

La crisis financiera global iniciada en 2007-2008 con la caída de bancos de inversión y posterior derrumbe de los mercados de valores, ha supuesto la participación de los gobiernos en rescates de entidades en inminente riesgo de quiebra y la reorganización del mapa financiero europeo. A la vista de este nuevo entorno bancario, el objetivo del presente trabajo de investigación es examinar las consecuencias que tienen los procesos de integración financiera derivados de la crisis sobre el grado de competencia en el sector bancario y la disponibilidad crédito.

El análisis empírico llevado a cabo en este trabajo para una muestra de 610 entidades bancarias procedentes de 16 países europeos, proporciona evidencia del 
impacto negativo que la crisis financiera global ha provocado en la oferta de crédito de los bancos en Europa y de cómo dicho impacto es contrarrestado por el incremento en el poder de mercado que algunas entidades han experimentado desde 2008. Este efecto positivo del poder de mercado bancario se observa especialmente en entornos con menor calidad legal e institucional y menor libertad económica, en países más exigentes en el cumplimiento del capital regulatorio, y allí donde las restricciones a las actividades bancarias no tradicionales son menores.

El resto del trabajo se estructura como se indica a continuación. A lo largo de las tres secciones siguientes $(2,3$ y 4$)$ se realiza el planteamiento teórico del análisis mediante una revisión de la literatura sobre los efectos de las crisis en la economía y la relación entre competencia bancaria y oferta de crédito. En la sección 5 se describe en detalle el análisis empírico desarrollado. Los resultados obtenidos son expuestos en la sección 6. Finalmente, la sección 7 ofrece las principales conclusiones del estudio.

\section{Las crisis financieras y sus efectos en la economía}

\subsection{Crisis financieras y economía real}

Dado el importante papel que el sistema financiero juega en la economía, mediante la reducción de costes de transacción, de problemas de selección adversa y riesgo moral, y la canalización y asignación eficiente de recursos hacia inversiones rentables, los efectos de las diferentes crisis bancarias acontecidas a lo largo de los años, han sobrepasado el ámbito financiero para, de forma inevitable, trasladarse al sector real de la economía.

La literatura previa ha puesto de manifiesto que los efectos negativos de las crisis bancarias sobre la economía real se asocian al canal de crédito. Los problemas de liquidez ante el aumento de morosidad y la necesidad de mantener un capital mínimo regulatorio obligan a las entidades a reducir la oferta de crédito. Como consecuencia, las empresas tienen más dificultades para acceder a la financiación externa que precisan para llevar a cabo su inversión y contribuir así al crecimiento económico.

Diversos autores han proporcionado evidencia empírica sobre el impacto de las crisis bancarias en el crecimiento económico que refuerza el papel del crédito como principal canal entre sector financiero y sector real. Kroszner et al. (2007) demuestran que el efecto negativo de las crisis sobre el crecimiento económico se da de manera particular en aquellos países cuyos sistemas financieros están más desarrollados. Dell' Ariccia et al. (2008) obtienen un mayor impacto sobre el crecimiento de los sectores industriales que por sus características son más dependientes de financiación bancaria. Además del canal crediticio, estudios previos también han resaltado la relevancia del canal de la inversión como mecanismo a partir del cual los efectos más negativos de las crisis bancarias se trasladan al sector real. A partir de una muestra internacional de empresas e industrias, Fernández et al. (2013) observan 
que en periodos de crisis financieras, el crecimiento económico es menor debido, tanto a la reducción en la cantidad de fondos prestables, como a los problemas de canalización y asignación eficiente de recursos hacia proyectos de inversión rentables.

Laeven y Valencia (2012) definen el año de inicio de una crisis como aquél en el que se dan signos significativos de desastre financiero en el sistema bancario. Ejemplos de signos de desastre financiero son las retiradas masivas de depósitos, las pérdidas relevantes por parte de los bancos o las liquidaciones de entidades financieras. Una crisis adquiere la consideración de sistémica en el momento en que se adoptan medidas de intervención política en respuesta a dicha situación. Reino Unido fue el primer país europeo en advertir síntomas de desastre financiero, allá por el 2007, año en el que se desencadena la crisis en Estados Unidos. En el resto de países no se materializó hasta un año más tarde.

El Gráfico 1 muestra la tasa de crecimiento interanual del PIBpc (Producto Interior Bruto por habitante) de la Unión Europea ${ }^{1}$ para un periodo de 20 años que incluye la crisis financiera global. Hasta 2007 el PIBpc creció anualmente a tasas comprendidas entre el 0,5 por 100 y cerca del 5 por 100. En el 2008, el PIB per cápita se reduce en un 0,34 por 100. Pero es en el año 2009 cuando el impacto de la crisis sobre el crecimiento económico se hace patente con una caída del PIB per cápita de 5,74 puntos porcentuales.

\section{GRÁFICO 1}

\section{CRECIMIENTO DEL PIBPC EN LA UNIÓN EUROPEA}

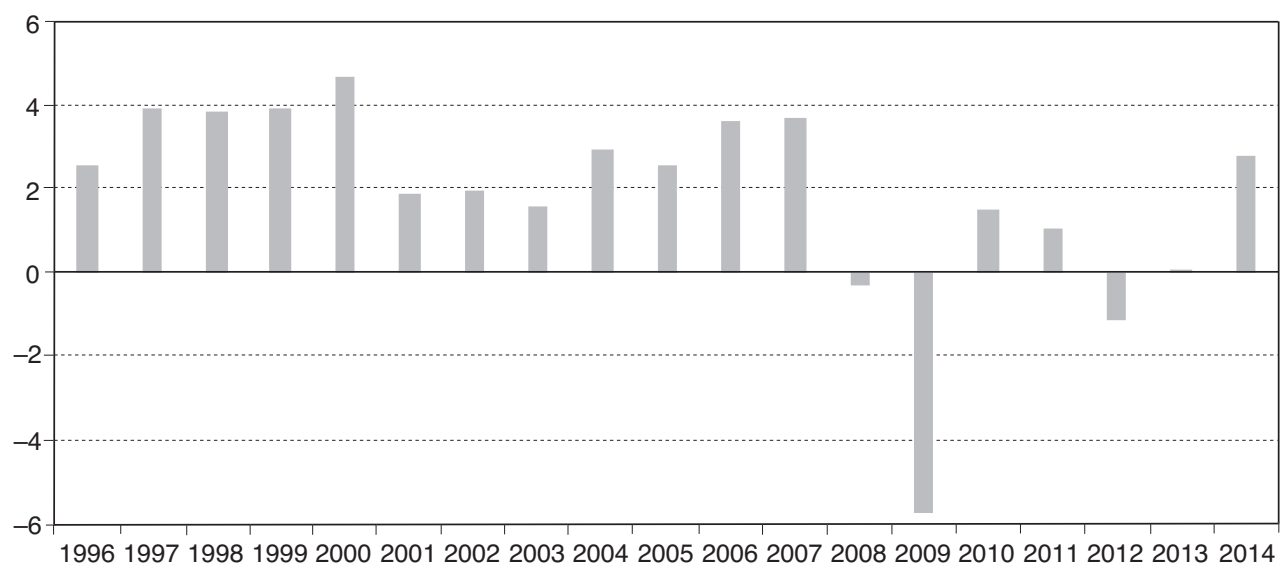

FUENTE: Elaboración propia a partir de datos del Banco Mundial.

\footnotetext{
${ }^{1}$ El PIB per cápita de la Unión Europea está calculado como la media del PIB per cápita de los 27 países que la componen.
} 
Otros autores han analizado el impacto directo de las crisis bancarias sobre la cantidad de crédito disponible para las empresas. Para una muestra de 6 economías emergentes, Love et al. (2007) obtienen resultados que evidencian una reducción del crédito comercial en los años posteriores a una crisis bancaria. Chava y Purnanandam (2011) se centran en el shock que experimentó el sistema bancario estadounidense durante la crisis rusa de 1998. Sus resultados ponen de manifiesto que los bancos cuya salud financiera se vio más afectada redujeron la cantidad de crédito e incrementaron el precio de los préstamos. En consecuencia, las empresas que confiaban en este tipo de financiación, sufrieron pérdidas elevadas durante ese periodo.

\subsection{Crisis financieras y poder de mercado bancario}

La cantidad de crédito no es la única característica del mercado bancario en la que se pueden advertir los efectos de los periodos de crisis. El nivel de competencia bancaria también es susceptible de sufrir cambios durante episodios turbulentos. Desde un punto de vista teórico, el efecto sobre la competencia bancaria no está claro. Por un lado, con objeto de evitar nuevos episodios de crisis, los bancos se comportarían de forma más prudente e invertirían en proyectos menos arriesgados $\mathrm{y}$, por ende, menos rentables. Los menores márgenes les harían perder poder de mercado, con lo que, en términos medios, aumentaría el grado de competencia en el sector. Por otro lado, los procesos de reestructuración bancaria que se suelen dar en épocas de crisis y que incluyen el cierre de entidades, fusiones y adquisiciones de bancos en situación de quiebra inminente, contribuyen a incrementar el poder de mercado de las entidades que logran mantenerse compitiendo en el sector.

Normalmente, como resultado de estas medidas de reestructuración, disminuye el número de bancos en el mercado (Laeven y Valencia, 2008; Wheelock, 2011). Además, los bancos que sobreviven a dichos procesos son los que han sabido hacer frente a los problemas de una manera más eficiente y están en posición de aumentar su cuota de mercado, reducir costes e incrementar márgenes. Si estos bancos consiguen hacerse con un mayor poder de mercado que antes de la crisis, el nivel de competencia en el sector sería menor.

Los siguientes gráficos (Gráfico 2 y Gráfico 3 ) muestran una comparativa de la estructura del mercado bancario en la Unión Europea siete años antes de la crisis, en el 2007 y siete años después de la crisis. Las dos primeras medidas muestran el grado de concentración medio del sector a partir de los datos obtenidos para los 27 países de la Unión Europea. Dichas medidas se calculan como el porcentaje de activos que las 5 (en un caso) y las 3 (en el otro) entidades de mayor tamaño acumulan respecto del total de activos del sistema bancario. El grado de concentración bancaria en el 2000 y en el 2007 es bastante similar. Sin embargo, en el 2014 hay una evidente mayor concentración con respecto al año de inicio de la crisis, en línea con los procesos de reestructuración bancaria que han tenido lugar en los últimos años. 


\section{GRÁFICO 2}

CONCENTRACIÓN DEL MERCADO BANCARIO

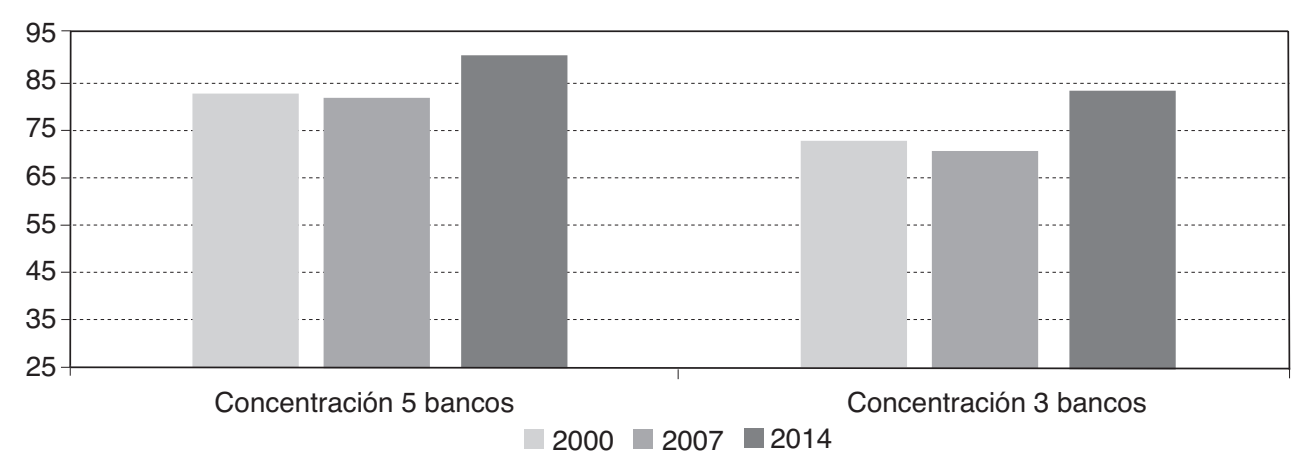

FUENTE: Elaboración propia a partir de datos del Banco Mundial.

Las otras dos medidas representan, respectivamente, el poder de mercado y el grado de competencia medios del sector a partir de los datos obtenidos para los 27 países de la Unión Europea. Mayores valores del índice de Lerner indican mayor poder de mercado, mientras que valores más negativos del indicador de Boone indican mayor grado de competencia bancaria. En consonancia con el efecto de la reestructuración bancaria, el poder de mercado ha ido en aumento desde la crisis, lo que resulta coherente con la disminución de la competencia, que en el 2014 alcanza niveles similares a los del año 2000.

\section{GRÁFICO 3}

PODER DE MERCADO Y COMPETENCIA BANCARIA

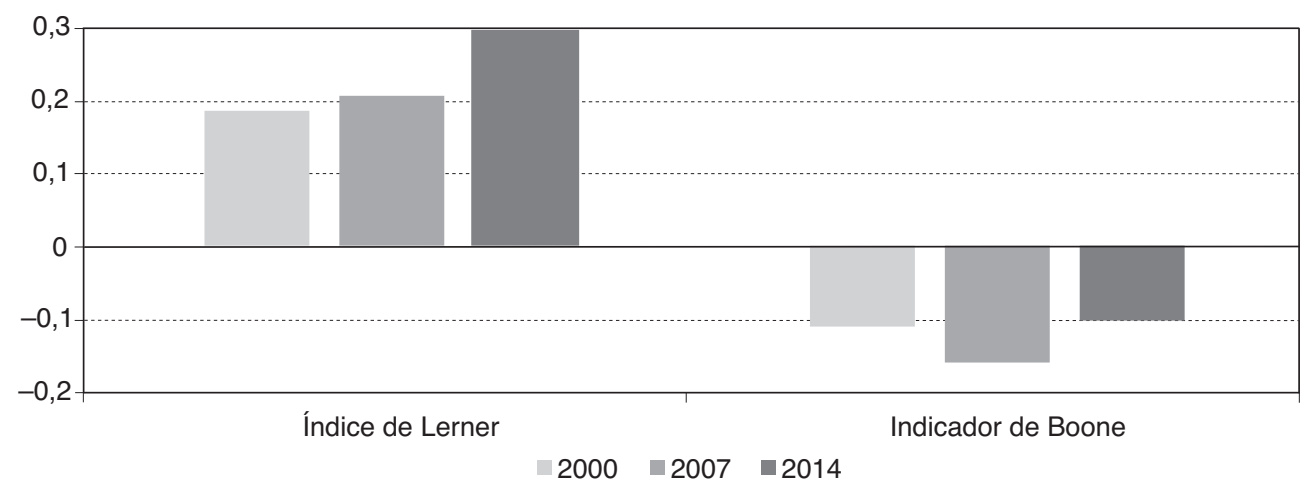

FUENTE: Elaboración propia a partir de datos del Banco Mundial. 
Siguiendo el mismo razonamiento y utilizando una muestra de 64 países y 67 episodios de crisis bancarias acontecidas entre 1989 y 2007, Cubillas y Suárez (2013) muestran que el nivel de poder de mercado bancario se incrementa tras un episodio de crisis bancaria. Sus resultados ponen de manifiesto que la calidad institucional fomenta el incremento en el poder de mercado bancario, mientras que las regulaciones a las actividades bancarias no tradicionales y las barreras de entrada en el sector, hacen que los incrementos en el poder de mercado sean menos importantes.

\section{Competencia bancaria y crédito}

El vínculo entre competencia bancaria y oferta de crédito ha sido también objeto de estudio en la literatura. Desde un punto de vista teórico, el hecho de que el acceso al crédito pueda verse afectado por el grado de poder de mercado bancario, depende de las más o menos intensas asimetrías de información. En una hipotética situación de ausencia de asimetrías de información en el mercado bancario, un mayor poder de mercado traería consigo un mayor coste de financiarse con crédito y una menor oferta del mismo (Klein, 1971). Por otro lado, un menor nivel de competencia bancaria fomenta las relaciones de confianza entre el banco y sus prestatarios (relationship banking), tan necesarias para recabar información fiable y favorecer el acceso a crédito en presencia de información asimétrica (Petersen y Rajan, 1994).

La evidencia empírica es mixta cuando se utilizan medidas de concentración como proxies de poder de mercado. A partir de datos de Estados Unidos, Petersen y Rajan (1994, 1995) y Berlin y Mester (1999) muestran que en mercados de crédito menos concentrados, las empresas están sujetas a menores restricciones de financiación. Por su parte, D'Auria et al. (1999), para una muestra de empresas italianas, y Degryse y Ongena (2005), para una muestra de empresas belgas, obtienen que un aumento de la concentración bancaria incrementa el coste de financiación bancaria para las empresas. Cetorelli y Gambera (2001) argumentan que la concentración del mercado bancario facilita la creación de relaciones de confianza entre los bancos y las empresas más jóvenes, y que esto explicaría la relación positiva que encuentran entre concentración bancaria y crecimiento económico en aquellos sectores más dependientes de financiación externa.

Otros estudios han asociado la relación entre poder de mercado bancario y suministro de crédito con la facilidad de los bancos para acceder a fuentes alternativas de fondos. Ciertas características individuales a nivel de banco, como el tamaño, la capitalización o la liquidez, determinan sus posibilidades de acceso a los mercados financieros. Asimismo, el poder de mercado podría ser un factor explicativo de las alternativas de inversión y financiación que tiene ante sí una entidad bancaria. Cabe esperar que aquellos bancos con un mayor poder de mercado tengan más facilidad para acceder a los mercados financieros en busca de nuevas formas de inversión y financiación. En consecuencia, estos bancos son más capaces de financiar la actividad 
crediticia y de compensar pérdidas procedentes de préstamos fallidos o reducciones transitorias de sus márgenes financieros.

Algunos autores han analizado la influencia de la competencia bancaria sobre la oferta de crédito después de un cambio en la política monetaria. Adams y Amel (2005) analizan si la estructura del sector bancario, medida a través del índice Herfindahl, afectó al suministro de crédito bancario a las pequeñas empresas estadounidenses durante el periodo 1996-2002. Sus resultados muestran que la concentración del mercado bancario supone un obstáculo a la transmisión de la política monetaria. Olivero et al. $(2011 \mathrm{a}, \mathrm{b})$ estudian cómo afecta la competencia bancaria a la transmisión de la política monetaria vía crédito en los países en desarrollo de Asia y Latinoamérica entre 1996 y 2006. Sus resultados son opuestos dependiendo de la medida de competencia utilizada. Con datos de Europa y Estados Unidos y para el periodo 1997-2010, Brissimis y Delis (2010) proporcionan evidencia sobre la respuesta de los bancos a un cambio en la política monetaria en función de su poder de mercado, que miden utilizando el estadístico de Rosse-Panzar. Brissimis et al. (2012) estudian el impacto del poder de mercado, medido a través del índice de Lerner y el indicador de Boone, en la reacción de los bancos a la hora de conceder crédito y asumir riesgos tras un cambio en la política monetaria. Utilizando una muestra de bancos de 12 países europeos y Estados Unidos, analizados para el periodo 1997-2010, sus resultados indican que la competencia bancaria favorece la transmisión de la política monetaria a través del crédito. Este y otros estudios recientes han considerado examinar un periodo de análisis que incluye la crisis financiera global, lo que permite comparar el efecto de la competencia bancaria sobre la oferta de crédito en tiempos de estabilidad y en tiempos de crisis (Gambacorta y Marques-Ibanez, 2011; Fungáčová et al., 2014; Leroy, 2014).

\section{Oferta de crédito tras la crisis global en función del poder de mercado bancario}

Teniendo en cuenta que los periodos de crisis tienen efectos sobre la estructura de mercado del sector bancario y que es posible establecer un vínculo entre esta y el volumen de fondos que los bancos están dispuestos a prestar, parece lógico que cambios en el nivel de competencia bancaria, ocurridos como consecuencia de una crisis, puedan modificar el impacto negativo que esta tiene sobre la oferta de crédito.

Si una crisis trae consigo procesos de reestructuración bancaria que reducen el número de bancos operando en el sector, y como consecuencia, el nivel de competencia del mismo, algunas de las entidades que sobreviven a estos procesos disfrutarán de un mayor poder de mercado. Estas se podrán permitir una menor reducción de su actividad crediticia al tener más fácil acceso a los mercados de capital en busca, tanto de recursos para financiarla, como de nuevas formas de inversión que permitan compensar reducciones transitorias de sus márgenes financieros. Por tanto, cabe esperar que aquellos bancos que experimenten un mayor incremento de su poder 
de mercado durante una crisis, no reduzcan tanto como otros bancos la cantidad de crédito disponible para prestar.

El incremento en el poder de mercado medio de los bancos podría diferir de unos países a otros. Cabe pensar que las fusiones y adquisiciones bancarias sean más factibles en aquellos países donde la situación económica no se ve tan severamente afectada por la crisis y los gobiernos estén en mejor posición de contribuir al buen término de dichos procesos de integración. Laeven y Valencia (2012) proponen varias medidas de severidad de la crisis. Una de ellas consiste en computar la reducción relativa que tiene lugar en el PIB del país respecto a la tendencia de crecimiento observada hasta el año antes de la crisis. Atendiendo a esta medida de severidad, en el Gráfico 4 se observa que en los sectores bancarios de los países que experimentaron menores reducciones del PIB $^{2}$, aumentó el poder de mercado medio ${ }^{3}$.

\section{GRÁFICO 4}

\section{PODER DE MERCADO MEDIO DE LOS BANCOS DEL PAÍS}

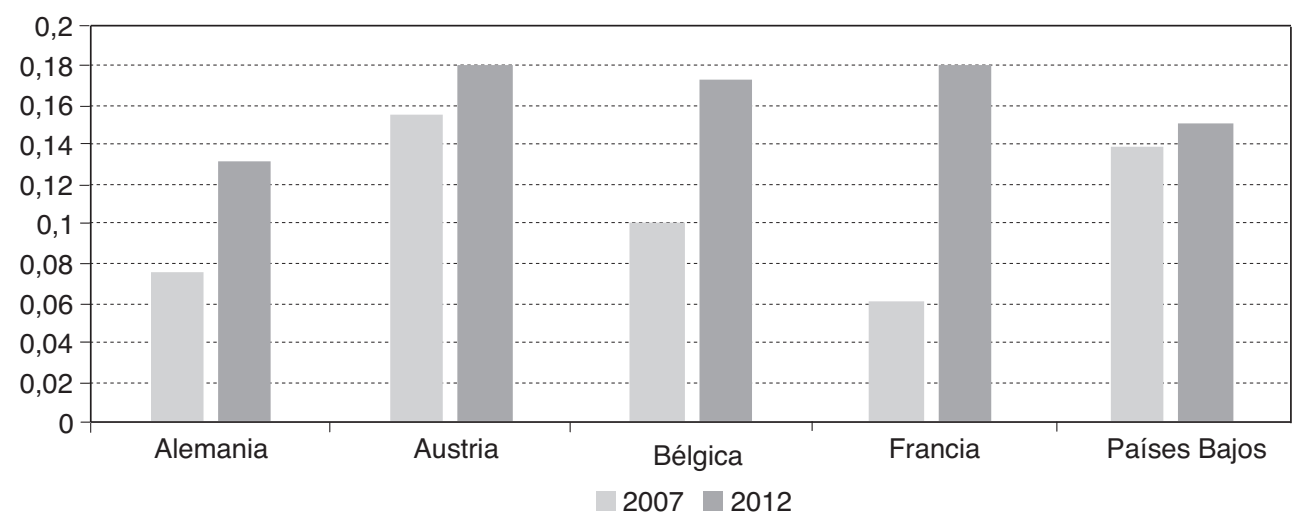

FUENTE: Elaboración propia a partir de datos del Banco Mundial.

La influencia de la competencia bancaria en el impacto de la crisis sobre la oferta de crédito podría estar condicionada por la calidad del entorno legal e institucional. La literatura de Law and Finance proporciona importante evidencia empírica sobre la contribución del marco legal e institucional al desarrollo financiero, que a su vez favorece el crecimiento económico al permitir un mayor acceso a financiación externa por parte de las empresas (La Porta et al., 1998; Rajan y Zingales, 1998). En

\footnotetext{
${ }^{2}$ Alemania, Austria, Bélgica, Francia y Países Bajos son los 5 países (de los 17 de la Unión Europea para los que está disponible el dato de la medida de severidad propuesta por Laeven y Valencia, 2012) que experimentaron una menor reducción del PIB en relación con la tendencia de crecimiento observada hasta el año antes de la crisis.

${ }^{3}$ Medido a través del Índice de Lerner.
} 
particular, una mayor protección de los derechos de propiedad está positivamente relacionado con el uso de fondos externos y una mayor protección de los derechos de los acreedores favorece la disponibilidad de recursos vía deuda para las empresas (La Porta et al., 1998, 2000; Demirgüç-Kunt y Maksimovic, 1999). El papel de la competencia como potencial atenuante del impacto negativo de la crisis sobre la cantidad de dinero que los bancos están dispuestos a prestar, podría ser más determinante en países con menor calidad institucional. Asimismo, el diferente grado de exigencia en el cumplimiento de los requerimientos de regulación bancaria también podría afectar a los cambios de estructura de mercado después de una crisis bancaria y por ende, a la cantidad de fondos prestados por los bancos. Todos estos aspectos serán contrastados a través del análisis empírico descrito en la siguiente sección.

\section{Análisis empírico}

\subsection{Muestra}

La base de datos empleada para llevar a cabo el contraste empírico contiene información económico-financiera a nivel individual para una muestra total de 610 bancos de 16 países de la Unión Europea. La información a nivel de banco procede de BankScope Database ${ }^{4}$. Siempre que ha resultado posible, se ha optado por la selección de información económico-financiera procedente de los estados financieros consolidados. Los valores de todas las variables relevantes para el estudio empírico se encuentran expresados en dólares americanos.

A fin de examinar el impacto de la crisis financiera global sobre el poder de mercado bancario y el crecimiento de los préstamos en Europa, el periodo muestral seleccionado abarca los años 1996 a 2012. La consideración de dicho periodo permite disponer de un periodo de precrisis (1996-2007) y un periodo de crisis (2008-2012) suficientemente amplio y válido para poder comparar la evolución de las variables de interés en torno al periodo de crisis financiera.

Además de la información sobre variables a nivel de entidad bancaria, se han obtenido datos referentes a variables macroeconómicas, a la calidad de las instituciones, a la estructura del mercado bancario y a la regulación del sector. Esta información se ha obtenido de diversas fuentes, tales como bases de datos del Fondo Monetario Internacional, del Banco Mundial o de la Fundación Heritage. La medida de severidad de la crisis ha sido obtenida de la base de datos de Laeven y Valencia $(2012)^{5}$. Con todo, la muestra final se compone de un panel incompleto de datos con un máximo de 4.932 observaciones a nivel de banco en un periodo de 17 años (1996-2012). En el Panel A del Cuadro 1, se muestra el listado de países finalmente

\footnotetext{
${ }^{4}$ BankScope, de Bureau van Dijk, ha sido hasta el 1 de enero de 2017 la más amplia base de datos sobre información bancaria. Contiene información detallada de 32.000 bancos de todo el mundo.

${ }_{5}^{5}$ Estos autores proporcionan información sobre 147 crisis bancarias acontecidas en todo el mundo entre 1970 y 2011.
} 
considerado en el estudio empírico, así como el número de entidades bancarias y observaciones por país.

\subsection{Metodología}

Dado que la crisis financiera global 2007/2008 ha podido afectar, tanto al nivel de competencia en el mercado bancario, como a la tasa de crecimiento de los préstamos, la metodología empírica empleada debe considerar la potencial dependencia simultánea del poder de mercado y del crecimiento de los préstamos respecto del episodio de crisis. También requiere el desarrollo de un modelo en dos etapas con la finalidad de tener en cuenta la posible endogeneidad entre el grado de competencia del mercado bancario y el crecimiento de la oferta crediticia. A fin de controlar ambas cuestiones, se combina un procedimiento 2SLS con estimaciones GMM (método generalizado de los momentos). La metodología GMM está específicamente diseñada para tratar tres aspectos econométricos de especial relevancia: (i) la presencia no observada de efectos específicos a nivel de banco, problema que se elimina al tomar primeras diferencias de las variables explicativas a nivel de entidad; (ii) la naturaleza dinámica tanto del poder de mercado como del crecimiento de los préstamos, aspecto que se considera al tomar valores retardados de la variables dependientes; y (iii) la posible endogeneidad a la que se pueden ver expuestas las variables explicativas, para lo cual se emplean valores retardados de las mismas como instrumentos.

El modelo básico pretende explicar cuál ha sido el efecto de la crisis financiera global sobre el crecimiento en los préstamos bancarios. El análisis efectuado permite examinar cuál ha sido el impacto directo de la crisis sobre la variación de los préstamos y cuál ha sido el papel desempeñado por el poder de mercado bancario en la explicación del efecto que el episodio de inestabilidad financiera ha tenido sobre el crecimiento de la oferta crediticia. La ecuación básica a estimar es la siguiente:

$$
\begin{aligned}
\operatorname{PPRESTAMOS}_{i, j, t} & \\
& =\beta_{0}+\beta_{1} \text { DPRESTAMOS } \\
& +\beta_{4} \text { SEVERIDAD }_{j, t}+\beta_{2} \text { LERNER }_{i, j, t}+\beta_{3} \text { CRISISIS }, t_{j, t} * \operatorname{SEVERIDAD}_{j, t}+\beta_{6} \text { BANCO }_{i, j, t} \\
& +\beta_{7} \text { MACRO }_{j, t}+\phi_{j, t}+\mu_{i}+\varepsilon_{i, j, t}
\end{aligned}
$$

donde $i, j, t$ se refieren al banco, país y año, respectivamente. La variable dependiente $\triangle P R E S T A M O S_{i j t}$ mide la tasa de variación anual del total de préstamos bancarios. El índice de Lerner $\left(L E R N E R_{i j t}\right)$ aproxima el grado de poder de mercado bancario y se relaciona negativamente con el nivel de competencia. En la primera etapa del modelo se calculan los valores pronosticados del índice de Lerner mediante una estimación GMM en la que los valores observados de dicho índice constituyen la variable dependiente. Los valores pronosticados de LERNER, obtenidos en esta primera etapa, se emplean en la segunda etapa como variables explicativas de la tasa de variación 
de los préstamos bancarios (modelo [1]). CRISIS $_{j t}$ es una variable dummy que toma valor 1 en los años de crisis financiera, y valor 0 en otro caso. SEVERIDAD ${ }_{j t}$ recoge la reducción relativa en el PIB de un país respecto a la tendencia de crecimiento observada hasta el año antes de la crisis financiera. El término de interacción CRISIS $_{j t} *$ SEVERIDAD $_{j t}$ indica el impacto de la crisis sobre el poder de mercado bancario en países donde el episodio de inestabilidad financiera ha sido más severo $\mathrm{y}$, donde, por ende, su efecto en el poder de mercado puede haber sido diferente.

Adicionalmente, se incluye en las estimaciones un vector de variables de control tanto a nivel de banco $\left(\right.$ BANCO $\left._{i j t}\right)$ como a nivel de país $\left(M A C R O_{j t}\right)$. Siguiendo a Fungáčová et al. (2014) y Leroy (2014), como variables de control a nivel de banco se incluyen: el tamaño, la liquidez, el capital, la Z-score, la proporción de ingresos por no intereses sobre el total de ingresos y una medida inversa al nivel de eficiencia bancaria. Como controles a nivel de país, se incluyen la tasa de crecimiento del PIB per cápita y el grado de concentración en el mercado bancario. Finalmente, $\phi_{j t}$ es un factor fijo que específicamente considera el efecto país-año con el fin de controlar por la existencia de características que son específicas a cada país en un año en particular. Este control permite capturar cualquier posible efecto no observado que sea común a todas las entidades bancarias en un país y en un año determinado y que no se haya incluido de manera específica en la regresión. Por ejemplo, la inclusión de $\phi_{j t}$ permitiría considerar la existencia de diferencias en la cobertura de información proporcionada por BankScope Database, que es más limitada en los primeros años del periodo muestral. $\mu_{i}$ es el efecto específico a nivel de banco que se asume constante para cada banco $i$ a lo largo de cada periodo $t . \varepsilon_{i j t}$ es el término de error.

El planteamiento 2SLS nos permite aislar dos efectos diferentes del episodio de crisis financiera global sobre la ecuación explicativa de la tasa de variación de los préstamos. El coeficiente $\beta_{2}$ indicaría en qué medida la crisis afecta al crecimiento de los préstamos bancarios como consecuencia de cambios en el poder de mercado de las entidades bancarias. $\beta_{3}$ capturaría el efecto directo del periodo de crisis financiera sobre la tasa de variación de los préstamos, independientemente de los cambios acontecidos en las instituciones financieras en términos de poder de mercado.

En la primera etapa, como variables explicativas del poder de mercado, se incluyen todas las referenciadas en el modelo [1]. Con el fin de controlar por el posible problema de endogeneidad del índice de Lerner, se incluyen adicionalmente en la regresión, a modo de instrumentos: (i) la variable KAOPEN, como medida de apertura de la cuenta de capital. Se trata de un índice de liberalización financiera desarrollado por Chinn e Ito (2008) y que estos autores han actualizado recientemente hasta 2014. Mayores valores del índice implican mayor apertura del país a transacciones transfronterizas de capital; (ii) el nivel de pérdidas de PIB asociadas al episodio de crisis en cada país (SEVERIDAD), obtenido de la base de datos de Laeven y Valencia (2012); y (iii) el valor retardado del índice de Lerner, calculado a partir de datos individuales de cada banco procedentes de BankScope Database.

Para comprobar la validez de estas variables como instrumentos del índice de Lerner es preciso corroborar que solo afectan a la variable dependiente de la segunda 
etapa $(\triangle P R E ́ S T A M O S)$ a través de su impacto en la dependiente de la primera de las ecuaciones (LERNER). Desde un punto de vista económico, es sabido que la presencia de capital público en la estructura de propiedad de las entidades bancarias reduce el nivel de competencia en el sector. En este sentido, los estudios que se han centrado en el vínculo entre la liberalización financiera y el riesgo bancario evidencian incrementos en el nivel de competencia tras episodios de liberalización, entendiéndose este como un canal a través del cual la estabilidad bancaria puede verse afectada (Keeley, 1990; Hellmann et al., 2000; Repullo, 2004; Cubillas y González, 2014). Cabe esperar entonces que el grado de liberalización financiera, aproximado por la variable $K A O P E N$, reduzca el poder de mercado bancario. Respecto al efecto del grado de severidad de la crisis financiera sobre el índice de Lerner, se espera que en aquellos países menos castigados por la crisis los gobiernos sean más capaces de contribuir al buen término de los procesos de integración bancaria y por tanto, el incremento en el poder de mercado medio sea mayor.

Además de los argumentos de carácter económico, la selección apropiada de los instrumentos requiere el cumplimiento de condiciones de tipo econométrico: los instrumentos deben estar estadísticamente correlacionados con la variable considerada como endógena y ser válidos, implicando su condición de ortogonalidad respecto de los residuos de la estimación. En primer término, es preciso comprobar la validez conjunta de los instrumentos seleccionados a través del test de Wald. La significatividad de este test sería un indicador de que los instrumentos (KAOPEN, SEVERIDAD y $L E R N E R_{t-1}$ ) son conjuntamente relevantes en la explicación del índice de Lerner. En segundo lugar, se emplea el test de sobreidentificación de restricciones de Hansen, que proporciona información sobre la validez de los instrumentos seleccionados. En concreto, el test debería confirmar la ausencia de correlación entre los instrumentos seleccionados y el término de error del modelo. También se considera relevante la necesidad de examinar la ausencia de correlación serial de segundo orden en los residuos de las primeras diferencias (m2). La ausencia de correlación serial de segundo orden indicaría que el modelo se encuentra, econométricamente, bien especificado.

El modelo econométrico básico representado en la ecuación [1] se extiende con el objetivo de examinar si las características definitorias del marco institucional de cada país y de la regulación bancaria pueden afectar a las relaciones existentes entre la crisis financiera, el poder de mercado bancario y la oferta crediticia. El modelo extendido se basa en la definición de submuestras en torno al valor mediano de cada una de las variables características del marco institucional y regulatorio. En concreto, las variables examinadas serán: el índice KKZ (Kaufman et al., 2009) obtenido como una media de los indicadores de gobernanza mundial proporcionados por el Banco Mundial; el índice de libertad económica Economic Freedom publicado anualmente por la Fundación Heritage; un indicador sobre regulación de capital y otro sobre el grado de restricciones legales a las actividades bancarias no tradicionales (Barth et al., 2008). 


\subsection{Variables}

5.3.1. Crisis financiera, poder de mercado, crecimiento de los préstamos

La variable CRISIS se define como una variable cualitativa que toma valor 1 para los años 2008-2012 ${ }^{6}$, y 0 en otro caso. Esta variable dummy permite identificar cuál es el efecto diferencial del poder de mercado bancario y de la oferta crediticia cuando se comparan el periodo previo al inicio de la crisis, con el periodo de crisis financiera.

Como medida del poder de mercado bancario se emplea el índice de Lerner (LERNER), variable ampliamente utilizada en la literatura más reciente sobre competencia en el sector bancario (Beck et al., 2013; Cubillas y Suárez, 2013; Cubillas y González, 2014, entre otros). Esta medida se define como la diferencia entre el precio (tasa de interés) y el coste marginal, expresada como un porcentaje del precio ${ }^{7}$. Se asume, por tanto, que la diferencia existente entre el precio y el coste marginal es la esencia del poder de monopolio. El índice de Lerner toma valor 0 en situación de competencia perfecta, y valor igual a 1 en el caso de una situación de monopolio perfecto. Finalmente, como medida de variación de la oferta de crédito, empleamos la tasa anual de crecimiento de los préstamos bancarios.

\subsubsection{Variables de control}

Actuando como controles, se incluyen dos vectores de variables. El primero de ellos, compuesto por un conjunto de variables de control definitorias de características propias de las entidades bancarias. El segundo vector se compone de variables de control a nivel macroeconómico. Entre los controles a nivel de entidad, se incluyen: el tamaño de los activos (TAMANOO), el ratio de liquidez (LIQUIDEZ), el ratio de capital de la entidad (CAPITAL), el nivel de riesgo, aproximado por la Z-Score (ZSCORE), la proporción de ingresos por no intereses sobre el total de ingresos (INGRESOS NO INT.), y una medida inversa de eficiencia aproximada por la proporción que representan los gastos no financieros sobre el total de activos bancarios (INEFICIENCIA).

El tamaño y los ratios de liquidez y capital son tres características propias de las entidades bancarias que se encuentran estrechamente relacionadas con el comportamiento del banco como prestamista, en tanto que se trata de rasgos especialmente relevantes para determinar el acceso de los bancos a los mercados financieros y, por tanto, pueden influenciar de manera directa la cantidad de crédito disponible para

${ }^{6}$ Siguiendo la información proporcionada por LAEVEN y VALENCIA (2012), se considera 2008 como el año de inicio de la crisis en todos los países de la muestra salvo en Reino Unido, donde se considera que el inicio de la crisis fue en 2007.

7 El cálculo del índice de Lerner a nivel de banco se basa en el procedimiento llevado a cabo por MAUDOS y FERNÁNDEZ DE GUEVARA (2004). 
prestar (Kashyap y Stein, 2000; Kishan y Opiela, 2000; Altunbas et al., 2002; Van den Heuvel, 2002; Ehrmann et al., 2003; Gambarcorta, 2005; Altunbas et al., 2009; Fungáčová et al., 2014; Leroy, 2014). TAMAÑO se define como el logaritmo natural del total de activos bancarios. LIQUIDEZ se calcula como la proporción de activos líquidos sobre el total de activos. CAPITAL es la proporción de fondos propios de la entidad sobre el total de activos. En el caso de bancos pequeños, poco líquidos y poco capitalizados cabría esperar mayores dificultades para mantener la oferta de crédito, en tanto que la compensación de pérdidas procedentes de préstamos fallidos con ganancias derivadas del acceso a los mercados de capitales y otras fuentes de financiación se presupone más complicada en el caso de dichas entidades.

Además de las características anteriormente mencionadas, se introducen en el análisis otras variables de control a nivel de banco (Altunbas et al., 2010). En tanto que el riesgo bancario ha sido un factor clave en la literatura previa para definir los efectos de los shocks monetarios en la oferta crediticia, se considera la Z-Score como medida inversamente relacionada con el nivel de riesgo de las entidades. El argumento que subyace a la inclusión de dicha variable se relaciona con la capacidad que los bancos con menores niveles de riesgo tienen para acceder a refinanciaciones en el mercado y hacer frente al impacto más negativo de cualquier tipo de shock. La Z-Score se define como la tasa de retorno de los activos más la ratio del capital sobre los activos y dividido todo ello por la desviación estándar de la tasa de retorno de los activos ${ }^{8}$. Laeven y Levine (2009) y Hadad et al. (2011), entre otros, emplean la Z-Score como medida del riesgo de insolvencia bancaria. La proporción de ingresos por no intereses sobre el total de ingresos bancarios (INGRESOS NO INT.) puede ser otro factor adicional que afecta al impacto de la crisis sobre la oferta de crédito. Loutskina y Strahan (2009), Altunbas et al. (2009), y Gambacorta y Marques-Ibañez (2011) muestran cómo las actividades de titulización reducen la efectividad de los shocks monetarios. Finalmente, como medida de eficiencia, se incluye el ratio entre los gastos no financieros ${ }^{9}$ sobre el total de activos del banco (INEFICIENCIA). Diferencias observadas en esta variable pueden capturar divergencias en el nivel de empleo o de salarios entre entidades financieras, así como aspectos relacionados con la definición del producto bancario y la calidad del servicio. Mayores valores de esta variable se atribuyen, por tanto, menores niveles de eficiencia.

En lo referente a las variables de control a nivel de país, se incluyen la tasa de variación anual del PIBpc y el nivel de concentración del mercado bancario, definido como el ratio entre los activos de los tres mayores bancos sobre el total de activos del sector bancario de cada país. Un aspecto crucial a la hora de determinar el impacto de la crisis financiera sobre el volumen de fondos es el que tiene que ver con la distinción entre un posible efecto demanda y el efecto oferta. Un episodio de inestabilidad financiera afecta a la estructura de balance de las entidades bancarias, provocando

\footnotetext{
${ }^{8}$ Para estimar las desviaciones estándar de la rentabilidad de los activos de cada institución bancaria se emplea una ventana móvil de 5 años.

${ }^{9}$ Gastos de personal y otros gastos no relacionados con los pagos de intereses.
} 
cambios tanto por el lado de la oferta, como por el lado de la demanda de préstamos. Durante periodos de crisis, la inversión corporativa se reduce, como consecuencia de las dificultades financieras de las empresas y la ausencia de oportunidades de inversión rentables. Por tanto, el efecto negativo de la crisis debido a cambios en oferta crediticia y el impacto negativo de la crisis como consecuencia de alteraciones en la demanda de fondos prestables, pueden aparecer de manera simultánea, dificultando así el análisis empírico. Por esta razón, tomando como referencia a Kashyap y Stein (1995), la literatura empírica ha optado por el uso de datos desagregados a nivel de banco a la hora de examinar los efectos reales de las crisis bancarias. Estos autores asumen que los bancos afrontan una demanda de préstamos homogénea para todas las entidades. De este modo, si se aprecian cambios entre entidades bancarias en lo que a su actividad crediticia se refiere, solo puede ser debido al hecho de que los diferentes tipos de bancos ajustan su oferta de fondos de manera diferente. El supuesto de demanda homogénea de préstamos se podría relajar si fuese posible emplear información a nivel individual de cada préstamo (Khwaja y Mian, 2008; Jiménez et al., 2012) En tanto que en el presente estudio no ha sido posible disponer de esta información, además del supuesto sobre demanda homogénea de fondos prestables, se incluye la tasa anual de crecimiento del PIB per cápita $(\triangle P I B p c)$ como variable de índole macroeconómica que pueda recoger, en parte, la variación de la demanda de crédito durante el periodo muestral examinado. Este es un procedimiento similar al argumentado recientemente en el trabajo de Leroy (2014), en el cual se examina cuál es la reacción de los bancos ante medidas de política monetaria del Banco Central Europeo, considerando, para ello, características individuales de las entidades bancarias y, en particular, su nivel de poder de mercado.

En el Cuadro 1 se presentan, por país, los valores medios de las principales variables analizadas en este estudio, así como sus principales estadísticos globales y la matriz de correlaciones. En el Cuadro 2 se muestra la matriz de correlaciones.

\subsubsection{Calidad institucional y regulación bancaria}

Si bien es cierto que el entorno europeo se caracteriza por un nivel de calidad institucional y regulatorio cuasi-homogéneo, persisten diferencias entre países basadas en el grado de orientación hacia la financiación de mercado o hacia la financiación bancaria las cuales se remontan a los propios orígenes legales (continental contra anglosajón) de cada país. Es por ello que, siguiendo la literatura Law and Finance, resulta relevante examinar si el impacto de la crisis financiera global sobre la disponibilidad de fondos prestables ha sido homogéneo en toda la muestra de países estudiados o se presentan diferencias dependiendo del marco institucional y regulatorio.

Como variables de carácter institucional se utiliza el índice KKZ y el índice de libertad económica Economic Freedom (LIBECO). Según Kaufman et al. (2009), la variable KKZ se calcula como el valor medio de seis indicadores de buen gobierno de los países que son proporcionados por el Banco Mundial: responsabilidad y 


\section{CUADRO 1}

ESTADÍSTICOS DESCRIPTIVOS

\begin{tabular}{|c|c|c|c|c|c|c|}
\hline País & Bancos & OBS. & Lerner & $\Delta$ Préstamos & Tamaño & Liquidez \\
\hline Alemania & 95 & 820 & 0,0980 & 0,0937 & 14,1617 & 0,3320 \\
\hline Austria & 48 & 382 & 0,1082 & 0,0736 & 14,0685 & 0,2736 \\
\hline Bélgica & 158 & 17 & 0,1018 & 0,1213 & 15,6994 & 0,3972 \\
\hline Dinamarca & 37 & 405 & 0,2103 & 0.1238 & 13,9292 & 0,1732 \\
\hline Eslovenia & 14 & 144 & 0,0647 & 0,1723 & 14,4797 & 0,2334 \\
\hline España & 37 & 272 & 0,1122 & 0,1623 & 15,1484 & 0,3127 \\
\hline Francia & 100 & 812 & 0,1482 & 0,0604 & 14,8236 & 0,2833 \\
\hline Grecia & 14 & 99 & 0,0549 & 0,2622 & 16,1288 & 0,2435 \\
\hline Holanda & 22 & 166 & 0,1247 & 0,1660 & 15,4836 & 0,2748 \\
\hline Hungría & 19 & 133 & 0,0739 & 0,1847 & 14,9761 & 0,2173 \\
\hline Irlanda & 9 & 60 & 0,2218 & 0,1217 & 17,4825 & 0,2286 \\
\hline Italia & 68 & 602 & 0,1875 & 0,1419 & 15,1888 & 0,2664 \\
\hline Letonia & 20 & 109 & 0,2618 & 0,2876 & 13,3746 & 0,3713 \\
\hline \begin{tabular}{|l|} 
Portugal \\
\end{tabular} & 15 & 133 & 0,1052 & 0,1944 & 15,1136 & 0,2548 \\
\hline Reino Unido & 77 & 499 & 0,1544 & 0,1389 & 14,7717 & 0,3979 \\
\hline Suecia & 18 & 138 & 0,1390 & 0,0939 & 14,8450 & 0,1308 \\
\hline Media & & & 0,1387 & 0,1222 & 14,7181 & 0,2883 \\
\hline Mediana & & & 0,1337 & 0,0781 & 14,4668 & 0,2273 \\
\hline Desviación típica & & & 0,0014 & 0,3165 & 1,9114 & 0,2164 \\
\hline Mínimo & & & 0 & $-0,7228$ & 9,3410 & 0,0086 \\
\hline Máximo & & & 0,4878 & 3,6316 & 19,7807 & 0,9317 \\
\hline País & Capital & Z-Score & Ing. no int. & Ineficiencia & $\triangle P I B P C$ & Concentración \\
\hline Alemania & 0,0991 & 1,2395 & 0,2359 & 0,0302 & 0,0130 & 0,4973 \\
\hline Austria & 0,1013 & 1,1961 & 0,2753 & 0,0305 & 0,0145 & 0,4713 \\
\hline Bélgica & 0,0619 & 1,0248 & 0,1885 & 0,0235 & 0,0148 & 0,5469 \\
\hline Dinamarca & 0,1108 & 1,1585 & 0.1897 & 0,0336 & 0,0093 & 0,3754 \\
\hline Eslovenia & 0,0913 & 1,1080 & 0,1729 & 0,0260 & 0,0275 & 0,7767 \\
\hline España & 0,1016 & 1,2238 & 0,2599 & 0,0261 & 0,0180 & 0,6639 \\
\hline Francia & 0,0830 & 1,1411 & 0,2520 & 0,0330 & 0,0117 & 0,2790 \\
\hline Grecia & 0,0909 & 0,6371 & 0,1058 & 0,0263 & 0,0084 & 0,9811 \\
\hline Holanda & 0,0859 & 1,2289 & 0,1498 & 0,0168 & 0,0160 & 0,8509 \\
\hline Hungría & 0,1015 & 1,0104 & 0,1717 & 0,0503 & 0,0264 & 0,7207 \\
\hline Irlanda & 0,0918 & 1,1651 & 0,1644 & 0,0135 & 0,0331 & 0,8902 \\
\hline Italia & 0,0934 & 1,2913 & 0,2461 & 0,0281 & 0,0029 & 0,5201 \\
\hline Letonia & 0,1190 & 0,7518 & 0,2404 & 0,0349 & 0,0591 & 0,8985 \\
\hline Portugal & 0,1107 & 1,1033 & 0,2997 & 0,0232 & 0,0110 & 0,7935 \\
\hline Reino Unido & 0,1232 & 1,1832 & 0,1852 & 0,0319 & 0,0147 & 0,4808 \\
\hline Suecia & 0,1107 & 1,2842 & 0,2465 & 0,0275 & 0,0178 & 0,5173 \\
\hline Media & 0,0985 & 1,1696 & 0,2259 & 0,0299 & 0,0140 & 0,9877 \\
\hline Mediana & 0,0774 & 1,2079 & 0,2047 & 0,0245 & 0,0167 & 0,4852 \\
\hline Desviación típica & 0,0826 & 0,4743 & 0,2065 & 0,0284 & 2,6861 & 0,2191 \\
\hline Mínimo & 0,0098 & $-1,5519$ & $-0,6093$ & 0,0013 & $-0,1292$ & 0,2052 \\
\hline Máximo & 0,7991 & 3,9983 & 0,9345 & 0,3730 & 0,1293 & 1 \\
\hline
\end{tabular}

NOTA: Definición variables. LERNER: índice de Lerner de poder de mercado; $\triangle$ PRÉSTAMOS: tasa de variación anual de los préstamos bancarios; TAMAÑO: logaritmo natural del total de activos; LIQUIDEZ: ratio entre activos más líquidos y total de activos bancarios; CAPITAL: proporción de fondos propios sobre el total de activos; Z-SCORE: nivel de estabilidad de la entidad; ING. NO INT.: porcentaje de ingresos obtenidos por actividad no tradicional respecto al total de ingresos; INEFICIENCIA: ratio entre gastos no financieros sobre total de activos; $\triangle \mathrm{PIBpc}$ tasa de variación anual del PIB per cápita; CONCENTRACIÓN: porcentaje de los activos de los tres mayores bancos del país sobre total de activos del sector bancario. 


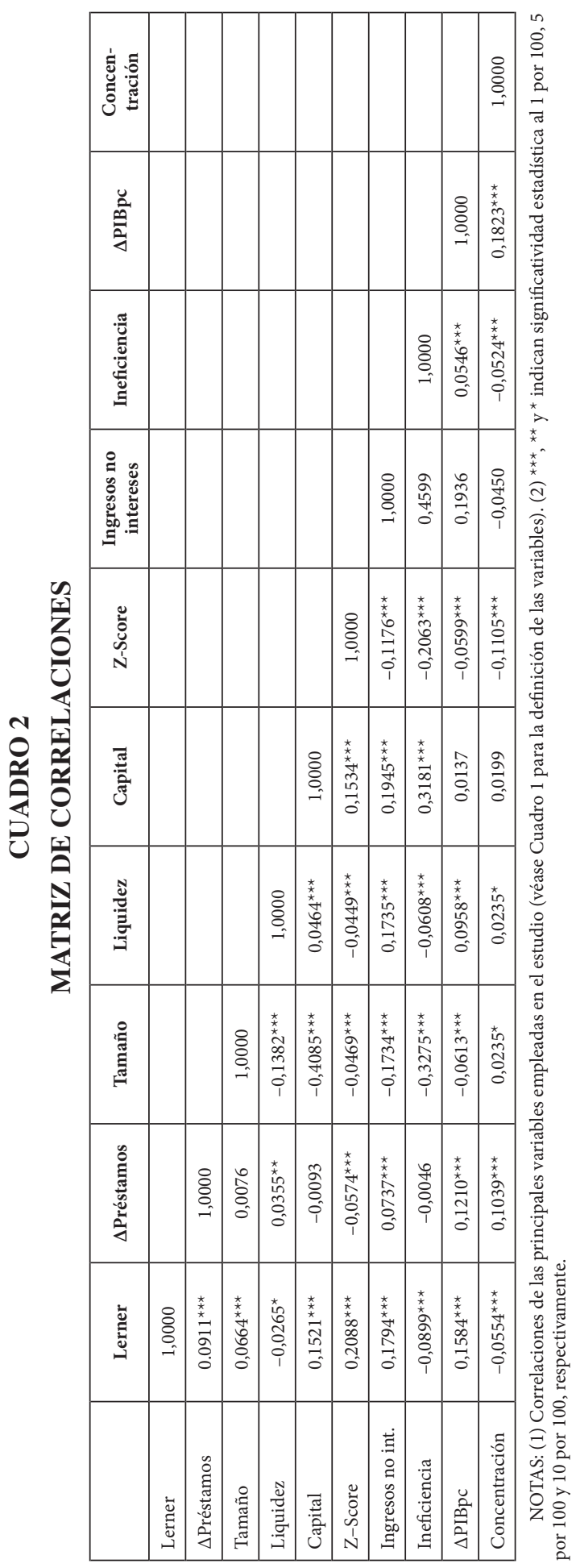


rendición de cuentas, estabilidad política, ausencia de violencia, efectividad del gobierno, calidad regulatoria, eficiencia legal y control de la corrupción. En términos teóricos, este índice puede variar entre $-2,5$ y 2,5. Mayores valores de esta variable indican un mayor desarrollo de la estructura institucional del país.

La segunda medida de calidad institucional es el índice de libertad económica (LIBECO) proporcionado por la Fundación Heritage. Este índice puede variar, teóricamente, entre 0 y 100. Mayores valores de esta variable indican un mayor grado de libertad económica. Trabajos como Demirgüic-Kunt et al. (2004) y Beck et al. (2006), entre otros, utilizan estas variables para propósitos de estudio similares a los expuestos en el presente artículo.

En lo que respecta a las variables de regulación bancaria consideradas, son dos: (1) la regulación sobre el capital bancario y (2) el nivel de restricciones legales a las actividades bancarias no tradicionales. En lo referente a la medida de capital, el índice considerado mide el nivel de exigencia legal en el cumplimiento de los requisitos sobre el capital bancario (REGCAPITAL). Mayores valores de este índice, que, en teoría, podría variar de un valor mínimo de 0 y un máximo de 3 , indican un mayor nivel de exigencia en el cumplimiento de los requisitos sobre regulación de capital.

Respecto a la regulación sobre actividades bancarias no tradicionales (ACTIVI$D A D E S$ ), se trata de una medida global que indica el grado de restricciones legales a las actividades bancarias no tradicionales (capital mobiliario, inmobiliario, sector de seguros y propiedad de empresas no financieras). Este índice señala si las actividades bancarias no tradicionales se encuentran: (1) no restringidas, (2) permitidas, (3) restringidas, (4) prohibidas. Teóricamente, este índice puede variar entre 1 y 16, donde mayores valores indican mayor grado de restricciones legales a las actividades bancarias consideradas como no tradicionales. Ambas medidas de regulación proceden de la base de datos Bank Regulation and Supervision Database, elaborada por Barth et al. (2008) y editada por el Banco Mundial ${ }^{10}$.

\section{Resultados}

6.1. Crisis, poder de mercado y crecimiento de los préstamos

El Cuadro 3 presenta los principales resultados sobre cómo la reciente crisis financiera ha afectado a la cantidad de crédito que los bancos europeos están dispuestos a prestar. Por un lado, se tiene en consideración el impacto global de la crisis sobre la oferta de crédito y, por otro, el efecto que específicamente tiene lugar a través de los cambios que se han producido en el poder de mercado de las entidades.

${ }_{10}$ Se consideran los valores medios del periodo de precrisis para las variables institucionales y regulatorias, con la finalidad de evitar posibles problemas de endogeneidad en las estimaciones. 
CUADRO 3

CRISIS, PODER DE MERCADO Y CRECIMIENTO DE LOS PRÉSTAMOS

\begin{tabular}{|c|c|c|c|c|c|}
\hline & \multicolumn{3}{|c|}{ PANEL A } & \multicolumn{2}{|c|}{ PANEL B } \\
\hline & $\begin{array}{c}\text { (1) } \\
\text { LERNER }\end{array}$ & $\stackrel{(2)}{\text { DPRÉSTAMOS }}$ & $\begin{array}{l}\text { (3) } \\
\text { DPRÉSTAMOS }\end{array}$ & $\begin{array}{c}\text { (4) } \\
\text { APRÉSTAMOS } \\
\text { PRE-CRISIS }\end{array}$ & $\begin{array}{l}\text { (5) } \\
\begin{array}{l}\text { APRÉSTAMOS } \\
\text { CRISIS }\end{array}\end{array}$ \\
\hline LERNER $_{\mathrm{T}-1}$ & $\begin{array}{c}0,4195 * * * \\
(4,79)\end{array}$ & - & - & - & - \\
\hline PRÉSTAMOS $_{\mathrm{T}-1}$ & $\begin{array}{c}0,00007 \\
(0,99)\end{array}$ & $\begin{array}{c}0,5521 * \\
(1,78)\end{array}$ & $\begin{array}{c}0,0981 * * \\
(2,22)\end{array}$ & $\begin{array}{c}0,1578 \\
(1,37)\end{array}$ & $\begin{array}{c}0,2787 * * \\
(2,34)\end{array}$ \\
\hline TAMAÑO & $\begin{array}{c}0,00008 \\
(0,55)\end{array}$ & $\begin{array}{l}-0,0537 \\
(-0,99)\end{array}$ & $\begin{array}{l}-0,0181 \\
(-0,19)\end{array}$ & $\begin{array}{c}0,0646 \\
(1,18)\end{array}$ & $\begin{array}{c}0,1619 \\
(1,12)\end{array}$ \\
\hline LIQUIDEZ & $\begin{array}{l}-0,0004 \\
(-0,42)\end{array}$ & $\begin{array}{l}-0,1599 \\
(-0,41)\end{array}$ & $\begin{array}{l}-0,2924 \\
(-0,66)\end{array}$ & $\begin{array}{c}0,0134 \\
(0,05)\end{array}$ & $\begin{array}{c}0,7466 \\
(1,37)\end{array}$ \\
\hline CAPITAL & $\begin{array}{c}0,0051 \\
(1,36)\end{array}$ & $\begin{array}{l}-0,6021 \\
(-0,26)\end{array}$ & $\begin{array}{c}0,2117 \\
(0,16)\end{array}$ & $\begin{array}{c}-0,9764 \\
(-1,08)\end{array}$ & $\begin{array}{r}3,6677 \\
(1,31)\end{array}$ \\
\hline Z-SCORE & $\begin{array}{c}0,00001 \\
(0,05)\end{array}$ & $\begin{array}{l}-0,0396 \\
(-0,35)\end{array}$ & $\begin{array}{c}-0,0265 \\
(-0,14) \\
\end{array}$ & $\begin{array}{c}0,1272 * \\
(1,92)\end{array}$ & $\begin{array}{c}-0,0730 \\
(-0,70)\end{array}$ \\
\hline INGRESOS NO INT. & $\begin{array}{c}0,0041 * * \\
(2,34)\end{array}$ & $\begin{array}{l}-0,7191 \\
(-1,40)\end{array}$ & $\begin{array}{c}-1,4862 * \\
(-1,89)\end{array}$ & $\begin{array}{l}-0,3692 \\
(-0,73)\end{array}$ & $\begin{array}{c}0,5904 * * * \\
(3,98)\end{array}$ \\
\hline INEFICIENCIA & $\begin{array}{c}-0,0503 * * * \\
(-2,99)\end{array}$ & $\begin{array}{l}2,7938 \\
(0,36)\end{array}$ & $\begin{array}{c}10,1878 * * \\
(2,12)\end{array}$ & $\begin{array}{c}-1,9286 \\
(-0,28)\end{array}$ & $\begin{array}{c}-3,0103 \\
(-1,61)\end{array}$ \\
\hline CRISIS & $\begin{array}{c}0,0004^{*} \\
(1,74)\end{array}$ & $\begin{array}{c}-0,0985^{*} \\
(-1,91) \\
\end{array}$ & $\begin{array}{c}-0,3117 * * * \\
\quad(-4,20)\end{array}$ & - & - \\
\hline SEVERIDAD & $\begin{array}{c}-0,00002 \\
(-1,20)\end{array}$ & - & - & - & - \\
\hline CRISIS * SEVERIDAD & $\begin{array}{c}-0,00002 * * \\
(-2,06)\end{array}$ & $\begin{array}{c}-0,0043 * * \\
(-2,41)\end{array}$ & $\begin{array}{c}0,0039 \\
(1,30)\end{array}$ & - & - \\
\hline LERNER & - & $\begin{array}{c}0,2891 \\
(0,41)\end{array}$ & - & $\begin{array}{l}0,1760 \\
(0,29)\end{array}$ & $\begin{array}{c}0,5838 * * \\
(2,52)\end{array}$ \\
\hline LERNERp & - & - & $\begin{array}{c}1,7903 * * \\
(2,19)\end{array}$ & - & - \\
\hline KAOPEN & $\begin{array}{c}-0,0049 * * \\
(-2,00)\end{array}$ & - & - & - & - \\
\hline$\triangle \mathrm{PIBPC}$ & $\begin{array}{c}0,00001 \\
(0,64)\end{array}$ & $\begin{array}{l}-0,0106 \\
(-1,62)\end{array}$ & $\begin{array}{l}-0,0075 \\
(-0,73)\end{array}$ & $\begin{array}{c}0,0171 * * \\
(2,25)\end{array}$ & $\begin{array}{c}-0,0141 * * * \\
(-3,08)\end{array}$ \\
\hline Concentración & $\begin{array}{c}0,0001 \\
(0,28)\end{array}$ & $\begin{array}{c}0,0590 \\
(0,87) \\
\end{array}$ & $\begin{array}{c}0,1539 * * \\
(2,13)\end{array}$ & $\begin{array}{c}-0,0127 \\
(-0,25)\end{array}$ & $\begin{array}{c}0,0206 \\
(0,29)\end{array}$ \\
\hline País-Año & Sí & Sí & Sí & Sí & Sí \\
\hline AR1 & $-5,79 * * *$ & $-2,75 * * *$ & $-7,10 * * *$ & $-3,89 * * *$ & $-4,32 * * *$ \\
\hline AR2 & $-0,58$ & 1,64 & 0,85 & 1,28 & 0,92 \\
\hline Test de Hansen & $23,06(17)$ & $3,73(8)$ & $10,81(8)$ & $23,97(20)$ & $18,20(16)$ \\
\hline Test de Wald Primera Etapa & $33,84 * * *$ & - & - & - & - \\
\hline Test de Wald & $535,49 * * *$ & $103,31 * * *$ & $86,05 * * *$ & $69,05 * * *$ & $189,67 * * *$ \\
\hline Test DWH & - & - & $5,03 * *$ & - & - \\
\hline N. ${ }^{\circ}$ de observaciones & 4.932 & 4.932 & 4.932 & 3.718 & 1.214 \\
\hline N. ${ }^{o}$ de bancos & 610 & 610 & 610 & 588 & 461 \\
\hline
\end{tabular}

NOTAS: (1) Resultados obtenidos para el análisis del efecto de la crisis financiera global sobre: 1) índice de poder de mercado bancario; 2) crecimiento de los préstamos; 3) crecimiento de los préstamos a través del efecto de la crisis sobre el nivel de competencia bancaria. Las columnas 4) y 5) muestran los datos obtenidos para el efecto del poder de mercado bancario sobre el crecimiento de los préstamos en el periodo previo a la crisis y en los años de crisis. El periodo muestral comprende los años 1996-2012. (2) ***,** y * indican significatividad estadística al 1 por 100,5 por 100 y 10 por 100 , respectivamente. 
Los valores no significativos del test de Hansen resultantes de aplicar el estimador GMM en sistemas confirman la validez de los instrumentos en todas las estimaciones. La hipótesis de ausencia de correlación serial de segundo orden en las primeras diferencias de los residuos no es rechazada y corrobora la consistencia de esta metodología en todas las estimaciones.

La columna (1) muestra los resultados de la ecuación de la primera etapa que permite obtener el valor pronosticado del índice de Lerner. El test de Wald de la primera etapa confirma la relevancia conjunta de las variables utilizadas como instrumentos (LERNER $R_{t-1}, K A O P E N$ y SEVERIDAD). El coeficiente positivo y estadísticamente significativo de LERNER $_{\mathrm{t}-1}$ indica que el poder de mercado de un banco depende de su poder de mercado en el año previo y pone de manifiesto la conveniencia de utilizar un modelo de ajuste parcial para explicar la naturaleza dinámica de esta variable. Por su parte, el coeficiente negativo y estadísticamente significativo de KAOPEN, revela que una mayor apertura financiera promueve la competencia en el sector bancario.

La dummy CRISIS muestra un coeficiente positivo y significativo, consistente con la reducción en el nivel de competencia bancaria que ha tenido lugar en la Unión Europea por término medio tras la crisis financiera global. El coeficiente negativo y significativo de la interacción CRISISSEVERIDAD es una señal de que el incremento medio que tiene lugar en el poder de mercado bancario tras la crisis, se da especialmente en aquellos países que experimentaron una menor reducción de su PIB respecto a la tendencia de crecimiento observada hasta el año antes de la crisis.

La situación económica, no tan severamente dañada de algunos países, favoreció una reestructuración ordenada mediante procesos de consolidación que configuraron un sector bancario menos competitivo. En contraste, en aquellos países donde la crisis trajo consigo consecuencias económicas más severas, los gobiernos no fueron capaces de apoyar procesos de fusión y adquisición para evitar la quiebra de bancos en dificultades, por lo que se configura un sector donde no necesariamente los bancos que continúan operando en él disfrutan de un mayor poder de mercado.

En cuanto a las variables de control, solo las variables INGRESOS NO INT. e INEFICIENCIA parecen tener un efecto significativo sobre el índice de Lerner. Los respectivos coeficientes de estas variables indican que cuanto mayor sea el nivel de ingresos que obtiene un banco más allá de sus márgenes por intereses y cuanto más eficiente sea en su actividad, mayor es su poder de mercado.

Las columnas (2) y (3) muestran los resultados de la ecuación que tiene la tasa de crecimiento anual de los préstamos como variable dependiente. La columna (2) contiene los resultados de la estimación considerando el valor observado de Lerner como variable explicativa, por lo que no tiene en cuenta que el poder de mercado y el crecimiento de los préstamos puedan ser simultáneamente explicados por la crisis. Es decir, esta ecuación no considera los posibles cambios en el poder de mercado durante la crisis como un canal a través del cual, esta pueda afectar a la oferta de crédito. Esta posibilidad sí aparece recogida en la columna (3), que contiene los resultados de la estimación considerando como variable explicativa el valor pronosticado de Lerner obtenido en la primera etapa. En esta ecuación cabe distinguir dos efectos. 
El coeficiente de la dummy CRISIS indica cómo se ha visto afectada la oferta de crédito tras la crisis independientemente de los cambios en el nivel de competencia bancaria. Por su parte, el coeficiente del valor pronosticado de Lerner (LERNERp) recoge el efecto específico de la crisis sobre la oferta de crédito a través de cambios en la competencia.

El coeficiente positivo y estadísticamente significativo obtenido para el valor retardado de la variable dependiente $\left(\triangle P R E ́ S T A M O S_{t-1}\right)$ sugiere que es necesario considerar la tasa de crecimiento de los préstamos en el año previo a través de un modelo de ajuste parcial que permita explicar la naturaleza dinámica de dicha variable. El coeficiente obtenido para la dummy CRISIS, negativo y significativo en ambas regresiones, indica que esta ha tenido un efecto reductor en la cantidad de crédito que los bancos están dispuestos a prestar. La interacción CRISIS * SEVE$R I D A D$ muestra un coeficiente negativo y significativo en la columna (2), lo que pone de manifiesto, que si no se tienen en cuenta los cambios ocasionados en el poder de mercado a raíz de la crisis, el impacto de esta sobre la oferta de crédito es más negativo allí donde tiene lugar una mayor reducción del PIB. El coeficiente del valor observado de LERNER en la columna (2) no es estadísticamente significativo para explicar la tasa de crecimiento de los préstamos. Sin embargo, el valor pronosticado de Lerner (LERNERp) en la columna (3) sí muestra un coeficiente positivo y significativo. Este último resultado indica que el efecto negativo de la crisis sobre la oferta de crédito es contrarrestado por el mayor poder de mercado en los bancos a consecuencia de la reestructuración. Se confirma entonces la hipótesis de que los bancos que experimentan un mayor incremento de su poder de mercado tras una crisis, no reducen tanto como otros bancos la cantidad de crédito que están dispuestos a prestar. Este resultado es consistente con los estudios que asocian poder de mercado bancario con mayor acceso a los mercados de capital y por ende, mayor capacidad para financiar la inversión crediticia y para compensar las reducciones transitorias de los márgenes financieros (Gambacorta y Marques-Ibanez, 2011; Fungáčová et al., 2014; Leroy, 2014).

El coeficiente significativo para el valor observado de Lerner en la columna (2) pero no significativo para el valor pronosticado del índice en la columna (3) evidencia la importancia de aplicar un procedimiento en dos etapas para examinar el papel de la competencia en el impacto que una crisis financiera tiene sobre la oferta de crédito bancario. Adicionalmente, el test de Durbin-Wu-Hausman (DWH) rechaza la hipótesis nula de que la introducción de variables instrumentales no tiene efecto en los coeficientes de la estimación. En consecuencia, la inclusión del valor pronosticado de Lerner (LERNERp) es aceptada.

A modo de robustez, el Panel B del Cuadro 4 recoge los resultados del análisis por submuestras de años. Aunque ambas columnas muestran los resultados de la ecuación que tiene como variable dependiente la tasa de crecimiento anual de los préstamos bancarios, cada una de ellas se refiere a un periodo diferente. La columna (4) contiene los resultados correspondientes a la estimación que considera todo el periodo anterior a la crisis y la columna (5) los de la estimación que considera 
todo el periodo post-crisis. Este análisis por submuestras permite ver cuál ha sido el efecto del poder de mercado sobre la oferta de crédito antes y después de la crisis. El coeficiente no significativo de Lerner en la columna (4) y significativo en la columna (5) confirma que es precisamente el aumento de poder de mercado que experimentan algunos bancos durante los procesos de reestructuración, lo que les hace menos sensibles al impacto negativo de la crisis y por tanto más capaces de no reducir tanto el suministro de crédito.

\subsection{Influencia del entorno institucional y regulatorio}

El Cuadro 4 recoge los resultados de analizar si el impacto global de la crisis sobre el crédito bancario y su efecto específico a través de la competencia pueden verse influidos por la calidad del entorno legal e institucional y por el grado de exigencia en el cumplimiento de la regulación bancaria. El Panel A del Cuadro 4 se refiere a la submuestra de países que disponían de una mayor calidad legal e institucional y donde existía una mayor exigencia regulatoria en los años anteriores al desencadenamiento de la crisis. El Panel B se corresponde con la submuestra de países cuya calidad legal e institucional y su nivel de exigencia regulatoria se encontraban por debajo del valor mediano de la Unión Europea durante el periodo previo a la crisis financiera global.

La dummy CRISIS tiene un coeficiente negativo y estadísticamente significativo en seis de las ocho estimaciones, confirmando la reducción global de la oferta de crédito bancario que ha tenido lugar en la Unión Europea después de la crisis. Solo en las dos primeras columnas de la tabla los coeficientes de esta variable no resultan significativos. Es decir, en aquellos países con una elevada calidad de sus instituciones y un alto grado de libertad económica, no se observa una reducción, como consecuencia de la crisis, de la cantidad de crédito que los bancos están dispuestos a prestar. El coeficiente negativo de la interacción CRISIS * SEVERIDAD indica que la oferta de crédito sí se ve reducida en estos entornos a pesar de la alta calidad institucional cuando la pérdida en términos del PIB es significativa.

La variable $L E R N E R$ muestra un coeficiente positivo y significativo en las columnas (3), (5), (6) y (8). Es decir, el efecto atenuante del poder de mercado en el impacto negativo de la crisis sobre la oferta de crédito se observa en países con menor calidad legal e institucional, menor libertad económica, más exigentes en el cumplimiento del capital regulatorio y con menores restricciones a las actividades que los bancos pueden realizar más allá de su negocio tradicional de préstamos y depósitos. Este resultado pone de manifiesto que el papel del poder de mercado bancario para reducir el impacto de la crisis sobre el crédito es más determinante allí donde la calidad institucional y la libertad económica no son suficientes para influir positivamente en el crecimiento de los préstamos. También es más determinante cuando a los bancos se les exige cumplir rigurosamente con unos mínimos de capital regulatorio. Una explicación a este resultado puede ser la importancia del poder 


\section{CUADRO 4}

\section{CRISIS, PODER DE MERCADO Y CRECIMIENTO DE LOS PRÉSTAMOS: INFLUENCIA DEL ENTORNO INSTITUCIONAL Y REGULATORIO}

\begin{tabular}{|c|c|c|c|c|c|c|c|c|}
\hline & \multicolumn{4}{|c|}{$\begin{array}{c}\text { PANEL A: } \\
\text { Por encima de la mediana }\end{array}$} & \multicolumn{4}{|c|}{$\begin{array}{c}\text { PANEL B: } \\
\text { Por debajo de la mediana }\end{array}$} \\
\hline & KKZ & LIBECO & $\begin{array}{c}\text { REG } \\
\text { CAPITAL }\end{array}$ & $\begin{array}{c}\text { ACTIVI- } \\
\text { DADES }\end{array}$ & KKZ & LIBECO & $\begin{array}{c}\text { REG } \\
\text { CAPITAL }\end{array}$ & $\begin{array}{l}\text { ACTIVI- } \\
\text { DADES }\end{array}$ \\
\hline PRÉSTAMOS $_{\mathrm{T}-1}$ & $\begin{array}{c}0,0419 \\
(0,21)\end{array}$ & $\begin{array}{c}0,2367 \\
(1,07)\end{array}$ & $\begin{array}{c}0,0321 \\
(0,38)\end{array}$ & $\begin{array}{c}-0,0201 \\
(-0,38)\end{array}$ & $\begin{array}{c}0,1390^{* * *} * \\
(2,94)\end{array}$ & $\begin{array}{c}0,0865^{*} \\
(1,69)\end{array}$ & $\begin{array}{c}0,1007 * * * \\
\quad(2,67)\end{array}$ & $\begin{array}{c}0,0969 * * \\
(1,99)\end{array}$ \\
\hline TAMAÑO & $\begin{array}{c}0,1051 * \\
(1,74)\end{array}$ & $\begin{array}{c}0,0069 \\
(0,14)\end{array}$ & $\begin{array}{c}-0,0009 \\
(-0,02)\end{array}$ & $\begin{array}{c}0,1124 * \\
(1,91)\end{array}$ & $\begin{array}{c}-0,0698 \\
(-1,10)\end{array}$ & $\begin{array}{c}-0,0940 \\
(-1,12)\end{array}$ & $\begin{array}{c}-0,1070 * * \\
(-2,14)\end{array}$ & $\begin{array}{c}-0,0875 \\
(-0,69)\end{array}$ \\
\hline LIQUIDEZ & $\begin{array}{c}-0,5341 \\
(-1,15)\end{array}$ & $\begin{array}{c}0,1670 \\
(0,39)\end{array}$ & $\begin{array}{c}0,1612 \\
(0,46)\end{array}$ & $\begin{array}{c}0,0198 \\
(0,04)\end{array}$ & $\begin{array}{c}0,2957 \\
(0,89)\end{array}$ & $\begin{array}{c}-0,5552^{*} \\
(-1,68)\end{array}$ & $\begin{array}{c}-0,1487 \\
(-0,45)\end{array}$ & $\begin{array}{c}-0,2981 \\
(-0,54)\end{array}$ \\
\hline CAPITAL & $\begin{array}{c}0,1984 \\
(0,16)\end{array}$ & $\begin{array}{c}-3,3701 * \\
(-1,85)\end{array}$ & $\begin{array}{c}-2,0824 \\
(-1,41)\end{array}$ & $\begin{array}{c}4,1309^{*} \\
(1,65)\end{array}$ & $\begin{array}{l}-0,9909 \\
(-0,69)\end{array}$ & $\begin{array}{c}-0,8770 \\
(-0,76)\end{array}$ & $\begin{array}{c}-1,8515 \\
(-1,52)\end{array}$ & $\begin{array}{c}-0,2859 \\
(-0,16)\end{array}$ \\
\hline Z-SCORE & $\begin{array}{c}0,1389 \\
(1,26)\end{array}$ & $\begin{array}{c}-0,0303 \\
(-0,29)\end{array}$ & $\begin{array}{c}0,1376 \\
(0,92)\end{array}$ & $\begin{array}{c}0,1501 \\
(0,78)\end{array}$ & $\begin{array}{c}-0,2313 \\
(-1,34)\end{array}$ & $\begin{array}{c}0,2184^{*} \\
(1,93)\end{array}$ & $\begin{array}{c}-0,1016 \\
(-1,10)\end{array}$ & $\begin{array}{c}-0,2826 \\
(-0,88)\end{array}$ \\
\hline $\begin{array}{l}\text { INGRESOS NO } \\
\text { INT. }\end{array}$ & $\begin{array}{l}1,2002 \\
(1,59)\end{array}$ & $\begin{array}{l}-0,6486 \\
(-0,73)\end{array}$ & $\begin{array}{l}-0,5315 \\
(-0,69)\end{array}$ & $\begin{array}{l}-0,4058 \\
(-0,62)\end{array}$ & $\begin{array}{c}-1,4550^{*} \\
(-1,88)\end{array}$ & $\begin{array}{l}-0,8026 \\
(-1,27)\end{array}$ & $\begin{array}{l}-0,1144 \\
(-0,26)\end{array}$ & $\begin{array}{c}-2,6797 * \\
(-1,68)\end{array}$ \\
\hline INEFICIENCIA & $\begin{array}{c}-7,6194 \\
(-1,23)\end{array}$ & $\begin{array}{c}12,3185 \\
(1,19)\end{array}$ & $\begin{array}{c}9,3570 \\
(1,52)\end{array}$ & $\begin{array}{c}5,4022 \\
(1,17)\end{array}$ & $\begin{array}{c}8,2582 * \\
(1,69)\end{array}$ & $\begin{array}{c}11,4748^{*} \\
(1,86)\end{array}$ & $\begin{array}{c}0,0862 \\
(0,02)\end{array}$ & $\begin{array}{c}15,3731^{* *} \\
(2,18)\end{array}$ \\
\hline CRISIS & $\begin{array}{c}0,1280 \\
(0,89)\end{array}$ & $\begin{array}{c}-0,6590 \\
(-0,80)\end{array}$ & $\begin{array}{c}-0,5344 * * * \\
(-4,26)\end{array}$ & $\begin{array}{c}-0,1951 * \\
(-1,94)\end{array}$ & $\begin{array}{c}-0,2466^{* * * *} \\
(-3,59)\end{array}$ & $\begin{array}{c}-0,3350^{* * * *} \\
(-2,96)\end{array}$ & $\begin{array}{c}-0,1224 * * \\
(-2,24)\end{array}$ & $\begin{array}{c}-0,4046 * * * \\
(-2,86)\end{array}$ \\
\hline $\begin{array}{l}\text { CRISIS * } \\
\text { SEVERIDAD }\end{array}$ & $\begin{array}{c}-0,0090 * * \\
(-2,09)\end{array}$ & $\begin{array}{r}0,0215 \\
(0,72)\end{array}$ & $\begin{array}{c}0,0156^{* * * *} \\
(2,65)\end{array}$ & $\begin{array}{l}-0,0004 \\
(-0,08)\end{array}$ & $\begin{array}{c}0,0022 \\
(0,56)\end{array}$ & $\begin{array}{c}0,0075^{* * *} \\
(2,96)\end{array}$ & $\begin{array}{c}0,0017 \\
(0,66)\end{array}$ & $\begin{array}{c}0,0058 \\
(1,39)\end{array}$ \\
\hline LERNERp & $\begin{array}{c}-0,0169 * \\
(-1,69)\end{array}$ & $\begin{array}{c}2,0276 \\
(1,18)\end{array}$ & $\begin{array}{c}1,6969^{*} \\
(1,69)\end{array}$ & $\begin{array}{c}0,1378 \\
(0,17)\end{array}$ & $\begin{array}{l}0,0187 * * \\
(2,50)\end{array}$ & $\begin{array}{c}0,0175^{*} \\
(1,84)\end{array}$ & $\begin{array}{l}0,6216 \\
(0,77)\end{array}$ & $\begin{array}{l}0,0310 * * \\
(2,32)\end{array}$ \\
\hline$\triangle \mathrm{PIBPC}$ & $\begin{array}{c}0,0025 \\
(0,36)\end{array}$ & $\begin{array}{c}-0,0128^{* *} \\
(-2,30)\end{array}$ & $\begin{array}{c}-0,0107 \\
(-1,46)\end{array}$ & $\begin{array}{c}-0,0123 \\
(-1,36)\end{array}$ & $\begin{array}{c}-0,0145^{* *} \\
(-2,20)\end{array}$ & $\begin{array}{c}0,0052 \\
(0,94)\end{array}$ & $\begin{array}{c}-0,0038 \\
(-0,90)\end{array}$ & $\begin{array}{c}-0,0006 \\
(-0,07)\end{array}$ \\
\hline CONCENTRACIÓN & $\begin{array}{c}0,1100 \\
(1,09)\end{array}$ & $\begin{array}{c}0,0656 \\
(0,83)\end{array}$ & $\begin{array}{c}-0,0579 \\
(-0,67)\end{array}$ & $\begin{array}{r}0,1037 \\
(1,51)\end{array}$ & $\begin{array}{c}0,1579 * \\
(1,86)\end{array}$ & $\begin{array}{c}0,2427 * \\
(1,83)\end{array}$ & $\begin{array}{c}0,1995^{* * * *} \\
(3,16)\end{array}$ & $\begin{array}{c}0,2345^{* *} \\
(2,14)\end{array}$ \\
\hline País-Año & Sí & Sí & Sí & Sí & Sí & Sí & Sí & Sí \\
\hline AR1 & $-2,40 * *$ & $-2,89 * * *$ & $-3,98 * * *$ & $-2,53 * *$ & $-6,31$ **** & $-5,02 * * *$ & $-5,95 * * *$ & $-6,13 * * *$ \\
\hline AR2 & 1,20 & 1,52 & 0,75 & 1,07 & 0,61 & 0,17 & 1,48 & 0,53 \\
\hline Test de Hansen & $18,87(24)$ & $9,42(15)$ & $12,70(9)$ & $10,35(9)$ & $11,37(8)$ & $15,17(14)$ & $8,49(9)$ & $4,33(8)$ \\
\hline Test de Wald & $47,84 * * *$ & $77,06 * * *$ & $91,31 * * *$ & $106,57 * * *$ & $92,14 * * *$ & $75,45^{* * *}$ & $110,12^{* * *}$ & $35,58 * * *$ \\
\hline $\begin{array}{l}\text { Número de } \\
\text { observaciones }\end{array}$ & 1.369 & 2.713 & 1.696 & 978 & 3.563 & 2.219 & 3.236 & 3.954 \\
\hline Número de bancos & 174 & 331 & 436 & 278 & 436 & 279 & 522 & 592 \\
\hline
\end{tabular}

NOTAS: (1) El cuadro recoge los resultados obtenidos para el análisis del efecto directo de la crisis financiera global sobre la tasa de crecimiento de los préstamos y del efecto indirecto de la crisis sobre la oferta de crédito a través de los cambios experimentados en el nivel de competencia bancaria, teniendo en cuenta diferencias entre países en términos de calidad institucional y regulación bancaria. En el PANEL A se presentan los resultados obtenidos para la submuestra de observaciones que se encuentran por encima de la mediana de las características institucionales y regulatorias. EL PANEL B muestra los resultados para la submuestra de observaciones por debajo de la mediana de tales características. El periodo muestral comprende los años 1996-2012. (2) ***, ** $\mathrm{y} *$ indican significatividad estadística al 1 por 100,5 por 100 y 10 por 100 , respectivamente. 
de mercado para acceder fácilmente a los mercados de capital en busca de nuevos inversores. Finalmente, el poder de mercado bancario juega un papel más relevante cuando el nivel de restricciones legales a las actividades que los bancos pueden realizar es bajo. En estos entornos, las entidades con mayor poder de mercado podrán compensar las pérdidas procedentes de préstamos fallidos con los ingresos obtenidos en actividades bancarias menos tradicionales.

\section{Conclusiones}

La literatura previa ha puesto de manifiesto que los efectos negativos de una crisis financiera sobre la economía real se asocian, generalmente, al canal de crédito, en tanto que es usual observar una reducción en la provisión de crédito bancario durante los años que siguen al estallido de la misma. En este trabajo se analiza el impacto de la crisis financiera global sobre la oferta de crédito bancario en 16 países de la Unión Europea. Los procesos de reestructuración a los que normalmente son sometidos los sectores bancarios durante los periodos de crisis contribuyen a incrementar el poder de mercado de los bancos que logran sobreponerse a las dificultades.

Si las entidades con mayor poder de mercado disfrutan de un mejor acceso a los mercados de capital y por ende, a fuentes de inversión y financiación alternativas, cabe esperar que no tengan tantos incentivos a reducir la cantidad de crédito disponible.

Metodológicamente, en este estudio se aplica un procedimiento en dos etapas combinado con la metodología GMM con la finalidad de diferenciar el impacto global de la crisis sobre la oferta de crédito y el efecto que específicamente tiene lugar a través de cambios en la competencia bancaria. El análisis llevado a cabo en este estudio para una muestra de 610 bancos europeos proporciona evidencia empírica del impacto negativo que la crisis financiera global ha provocado en la oferta de crédito de los bancos europeos y de cómo dicho impacto es contrarrestado por el efecto que específicamente tiene lugar a través del incremento en el poder de mercado que algunas entidades han experimentado desde 2008.

Los resultados obtenidos también ponen de manifiesto que el papel del poder de mercado bancario para mitigar el impacto de la crisis sobre el suministro de crédito es más determinante en entornos con menor calidad legal e institucional y menor libertad económica, en países más exigentes en el cumplimiento del capital regulatorio, y allí donde no existen elevadas restricciones a las actividades que los bancos pueden realizar más allá de su negocio tradicional de préstamos y depósitos.

Esta investigación trae consigo algunas implicaciones en términos de política regulatoria. Los resultados sugieren que la legislación sobre política antimonopolio debería tener en cuenta la relevancia del poder de mercado para reducir el impacto negativo de las crisis sobre la oferta de crédito bancario. También arroja luz sobre la importancia de adoptar medidas que fomenten un mayor poder de mercado bancario durante las crisis en aquellos países donde la calidad de las instituciones resulte ser 
más moderada. Finalmente, el análisis sugiere que las restricciones a las actividades bancarias podrían ser un impedimento al efecto atenuante que ejerce el poder de mercado bancario en el impacto de las crisis sobre la cantidad de crédito que los bancos están dispuestos a prestar.

\section{Referencias bibliográficas}

[1] ADAMS, R. y AMEL, D. (2005). «The effects of local banking market structure on the bank lending channel of monetary policy». Board of Governors of the Federal Reserve System, Working Paper, 16.

[2] ALTUNBAS, Y.; FAZYLOV, O. y MOLYNEUX, P. (2002). «Evidence on the bank lending channel in Europe». Journal of Banking and Finance, 26 (11), 2093-2110.

[3] ALTUNBAS, Y.; GAMBACORTA, L. y MARQUES-IBANEZ, D. (2009). «Securitisation and the bank lending channel». European Economic Review, 53 (8), 996-1009.

[4] ALTUNBAS, Y.; GAMBACORTA, L. y MARQUES-IBANEZ, D. (2010). «Bank risk and monetary policy». Journal of Financial Stability, 6 (3), 121-129.

[5] BARTH, J. R.; CAPRIO, G. jr y LEVINE, R. (2008). «Bank regulations are changing: for better or worse?». Comparative Economic Studies, 50 (4), 537-563.

[6] BECK, T.; DE JONGHE, O. y SCHEPENS, G. (2013). «Bank competition and stability: cross country heterogeneity». Journal of Financial Intermediation, 22, 218-244.

[7] BECK, T.; DEMIRGÜÇ-KUNT, A. y MAKSIMOVIC, V. (2006). «The influence of financial and legal institutions on firm size». Journal of Banking and Finance, 30: 29953015.

[8] BERLIN, M. y MESTER, L. J. (1999). «Deposits and relationship lending». Review of Financial Studies, 12, 579-607.

[9] BRISSIMIS, S. y DELIS, M. (2010). «Bank heterogeneity and monetary policy transmission». ECB Working Paper, 1233.

[10] BRISSIMIS, S.; DELIS, M. y IOSIFIDI, M. (2012). «Bank market power and monetary policy transmission». MPRA Paper 49206. University Library of Munich.

[11] CETORELLI, N. y GAMBERA, M. (2001). «Banking market structure, financial dependence and growth: international evidence from industry data». Journal of Finance, 56, 617-648.

[12] CHAVA, S. y PURNANANDAM,A. (2011). «The effects of banking crises on bank-dependent borrowers». Journal of Financial Economics, 99, 755-786.

[13] CHINN, M. y ITO, H. (2008). «A new measure of financial openness». Journal of Comparative Policy Analysis, 10 (3), 309-322.

[14] CUBILLAS, E. y GONZÁLEZ, F. (2014). «Financial liberalization and bank risk-taking: International evidence». Journal of Financial Stability, 11, 32-48.

[15] CUBILLAS, E. y SUÁREZ, N. (2013). «Bank market power after a banking crisis: Some international evidence». The Spanish Review of Financial Economics, 11, 13-28.

[16] D'AURIA, C.; FOGLIA, A. y REEDTZ, P. (1999). «Bank interest rates and credit relationship in Italy». Journal of Banking and Finance, 23, 1067-1093.

[17] DEGRYSE, H. y ONGENA, S. (2005). «Distance, Lending Relationships and Competition». Journal of Finance, 60, 231-266. 
[18] DELL'ARICCIA, G.; DETRAGIACHE, E. y RAJAN. R. (2008). «The real effects of banking crises». Journal of Financial Intermediation, 7, 89-112.

[19] DEMIRGÜÇ-KUNT, A.; LAEVEN, L. y LEVINE, R. (2004). «Regulations, market structure, institutions, and the cost of financial intermediation». Journal of Money, Credit and Banking, 36, 593-622.

[20] DEMIRGÜÇ-KUNT, A. y MAKSIMOVIC, V. (1999). «Institutions, financial markets and firm debt maturity». Journal of Financial Economics, 54: 295-336.

[21] EHRMANN, M.; GAMBACORTA, L.; MARTINEZ, J.; SEVESTRE, P. y WORMS, A. (2003). Financial systems and the role of banks in monetary policy transmission in the euro area. Cambridge University Press.

[22] FERNÁNDEZ, A. I.; GONZÁLEZ, F. y SUÁREZ, N. (2013). «The real effects of banking crises: Finance or asset allocation effects? Some international evidence». Journal of Banking and Finance, 37, 2419-2433.

[23] FUNGÁČOVÁ, Z.; SOLANKO, L. y WEILL, L. (2014). «Does competition influence the bank lending channel in the euro area?». Journal of Banking and Finance, 49, 356366.

[24] GAMBACORTA, L. (2005). «Inside the bank lending channel». European Economic Review, 49, 1737-1759.

[25] GAMBACORTA, L. y MARQUES-IBANEZ, D. (2011). «The bank lending channel: lessons from the crisis». Economic Policy, 26 (66), 135-182.

[26] HADAD, M. D.; AGUSMAN, A.; MONROE, G.S.; GASBARRO, D. y ZUMWALT, J.K. (2011). «Market discipline, financial crisis and regulatory changes: evidence from Indonesian banks». Journal of Banking and Finance, 35, 1552-1562.

[27] HELLMANN, T. F.; MURDOCK, K. C. y STIGLITZ, J. E. (2000). «Liberalization, moral hazard in banking, and prudential regulation: are capital requirements enough?». American Economic Review, 90 (1), 147-165.

[28] JIMENEZ, G.; ONGENA, S.; PEYDRO, J. y SAURINA, J. (2012). «Credit supply and monetary policy: identifying the bank balance-sheet channel with loan applications». American Economic Review, 102, 2301-2326.

[29] KASHYAP, A. y STEIN, J. (1995). «The impact of monetary policy on bank balance sheets». Carnegie-Rochester Conference Series on Public Policy, June, 151-195.

[30] KASHYAP, A. y STEIN, J. (2000). «What do a million observations in banks say about the transmission of monetary policy?». American Economic Review, 90, 407-428.

[31] KAUFMAN, D.; KRAAY, A. y MASTRUZZI, M. (2009). «Governance matters VIII: Aggregate and individual governance indicators for 1996-2008». Policy Research Working Papers, World Bank.

[32] KEELEY, M. C. (1990). «Deposit insurance, risk, and market power». American Economic Review, 80, 1183-1200.

[33] KHWAJA, A. y MIAN, A. (2008). «Tracing the impact of bank liquidity shocks: evidence from an emerging market». American Economic Review, 98, 1413-1442.

[34] KISHAN, R. y OPIELA, T. (2000). «Bank size, bank capital, and the bank lending channel». Journal of Money, Credit and Banking, 32, 121-141.

[35] KLEIN, M. A. (1971). «A theory of the banking firm». Journal of Money, Credit and Banking, 3, 205-218.

[36] KROSZNER, R. S.; LAEVEN, L. y KLINGEBIEL, D. (2007). «Banking crises, financial dependence and growth». Journal of Financial Economics, 84: 187-228. 
[37] LA PORTA, R.; LOPEZ DE SILANES, F. y SHLEIFER, A. (1998). «Law and finance». Journal of Political Economy, 106: 1113-1155.

[38] LA PORTA, R.; LÓPEZ DE SILANES, F.; SHLEIFER, A. y VISHNY, R. (2000). «Investor protection and corporate governance». Journal of Financial Economics, 58, 3-27.

[39] LAEVEN, L. y LEVINE, R. (2009). «Bank governance, regulation and risk taking». Journal of Financial Economics, 93, 259-275.

[40] LAEVEN, L. y VALENCIA, F. (2008). «Systemic banking crises: A new database». IMF Working Paper WP/08/224.

[41] LAEVEN, L. y VALENCIA, F. (2012). «Systemic banking crises database: An update». IMF Working Paper WP/12/163.

[42] LEROY, A. (2014). «Competition and the bank lending channel in Eurozone». Journal of International Financial Markets, Institutions \& Money, 31, 296-314.

[43] LOUTSKINA, E. y STRAHAN, P. E. (2009). «Securitization and the declining impact of bank finance on loan supply: evidence from mortgage originations». Journal of Finance, 64, 861-889.

[44] LOVE I.; LORENZO A. P. y SARRIA-ALLENDE, V. (2007). «Trade credit and bank credit: Evidence from recent financial crises». Journal of Financial Economics, 83, 453469.

[45] MAUDOS, J. y FERNÁNDEZ DE GUEVARA, J. (2004). «Factors explaining the interest margin in the banking sectors of the European Union». Journal of Banking and Finance, 28, 2259-2281.

[46] OLIVERO, M. P.; LI, Y. y JEON, B. N. (2011a). «Consolidation in banking and the lending channel of monetary transmission». Journal of International Money and Finance, 30, 1034-1054.

[47] OLIVERO, M. P.; LI, Y. y JEON, B. N. (2011b). «Competition in banking and the lending channel: evidence from bank-level data in Asia and Latin America». Journal of Banking and Finance, 35, 560-571.

[48] PETERSEN, M. A. y RAJAN, R. G. (1994). «The benefits of lending relationships: Evidence from small business data». Journal of Finance, 49, 1367-1400.

[49] PETERSEN, M. A. y RAJAN, R. G. (1995). «The effect of credit market competition on lending relationships». Quarterly Journal of Economics, 110, 407-443.

[50] RAJAN, R. G. y ZINGALES, L. (1998). «Financial dependence and growth». American Economic Review, 88: 559-586.

[51] REPULLO, R. (2004). «Capital requirements, market power, and risk-taking in banking». Journal of Financial Intermediation, 13, 156-182.

[52] VAN DEN HEUVEL, S. (2002). «Does bank capital matter for monetary transmission?». Economic Policy Review, Federal Reserve Bank of New York, 259-265.

[53] WHEELOCK D. C. (2011). «Banking industry consolidation and market structure: Impact of the financial crisis and recession». Federal Reserve Bank of St. Louis Review, November/December, 93 (6), 419-38. 